\title{
ASSOCIATION OF BLOOD LIPIDS, NON-HDL- CHOLESTEROL AND LIPID RATIOS WITH EARLY ONSET MYOCARDIAL INFARCTION IN A BANGLADESHI POPULATION
}

\author{
$\mathrm{SKHAN}^{1}$, MM HOQUE${ }^{2}$
}

\begin{abstract}
Objective-To explore the status of blood Lipids, non-HDL-Cholesterol and Lipid Ratios in early onset Myocardial Infarction in a Bangladeshi population.

Design- A case control study involving 50 early onset Myocardial Infarction patients as cases (age $<45$ years) and 50 late onset MI patients as control

(age $>60$ years). It was carried out from January 2006 to December 2007 in the Department of Biochemistry, Bangabandhu Sheikh Mujib Medical University (BSMMU), Dhaka, Bangladesh.

Results- Serum Total cholesterol, Triacylglycerol and TAG/TC ratio found significantly raised in cases compared to controls; but with respect to Low Density Lipoprotein-cholesterol ( LDL-C), High Density Lipoprotein-Cholesterol(HDL-C), non-HDL-C, TC/HDL-C ratio, LDL-C/HDL-C ratio cases \& controls found to be identical.
\end{abstract}

Conclusion - Hypercholesterolemia and hypertriglyceridaemia are associated with early onset Myocardial infarction.

\section{Introduction}

Myocardial infarction is the lethal manifestation of Coronary Heart Disease (CHD) that may lead to sudden death. Clinical and epidemiological studies have documented that several types of risk factors such as advanced age, male sex, family history of myocardial infraction, increased serum total cholesterol and LDL-Cholesterol, decreased serum HDL-Cholesterol, smoking, hypertension and diabetes mellitus are associated with premature MI. ${ }^{1}$. In fact, the figures in young patients may be lower than actual because of atypical presentation and reluctance to submit themselves for further investigations ${ }^{2}$. Growing evidences suggest that peoples of Indian subcontinent including ours are more prone to early onset MI with low prevalence of conventional risk factors of MI but high prevalence of other newly emerging multidimensional risk factors which are yet to be explored in-depth. Sedentary life style, adoption of western acculturation and higher consumption of calories, saturated fat, tobacco and alcohol contribute to obesity, dyslipidaemia, hypertension (HTN), diabetes mellitus (DM) and hyperuricaemia and increase the risk of early onset MI ${ }^{3}$. This global phenomenon of prematurity and severity suggests that the disease starts at an early age and has a malignant and progressive course ${ }^{3}$.

In the western population incidence of $\mathrm{MI}$ in the young is up to $5 \%$ as compared to $12-16 \%$ in Indians. In some studies in India the percentage of patients below the age of 45 years suffering from AMI is reported as high as $25-40 \%{ }^{4,5}$.

Early onset MI is defined as cardiac events occurring before the age of 55 years in men and 65 years in women. In its severe form it happens below the age of 40 years in either sex ${ }^{6}$. Cutoff age of forty five years has been used in most studies to define young onset MI 7 .

\section{Materials \& Methods}

This case control study was carried out from January 2006 to December 2007 in the department of Biochemistry, Bangabandhu Sheikh Mujib Medical University (BSMMU), Dhaka, Bangladesh. Ethical

1. Department of Biochemistry, Bangabandhu Sheikh Mujib Medical University (BSMMU), Dhaka, Bangladesh.

2. Professor, Department of Biochemistry, Bangabandhu Sheikh Mujib Medical University (BSMMU), Dhaka, Bangladesh.

Correspondence : Dr. MM Hoque, Bangabandhu Sheikh Mujib Medical University (BSMMU), Dhaka, Bangladesh 
clearance was taken from Departmental and central ethical review committee, BSMMU. A total 100 myocardial infarction subjects of both sexes were selected for the study; of which 50 were early onset myocardial infarction patients (age $<45$ years) designated as case \& rest 50 were late onset myocardial infarction patients (age $>60$ years) designated as control.

$5 \mathrm{ml}$ fasting venous blood was collected from each subject with all aseptic precautions and allowed to clot at room temperature and then centrifuged for 1015 minutes. The separated serum was stored at -35 ${ }^{0} \mathrm{C}$ until used for estimation.

\section{Lab Methods}

Estimation of serum total cholesterol concentration:

Enzymatic end point (CHOD-PAP) method $^{8}$.

Estimation of serum Triacylglycerol concentration:

Enzymatic colorimetric GPO-PAP method ${ }^{9}$.

Estimation of serum HDL-C concentration:

Enzymatic colorimetric phosphotungstate/ magnesium method ${ }^{10}$.

Calculation of LDL-C concentration:

Fried Wald formula ${ }^{11}$.

\section{Results and Observations}

The age and sex pattern is shown on Table-I and the comparison of Lipid profile, non-HDL-C and lipid ratios between cases \& control is depicted on Table-II.

Table - I

Grouping of the study subjects with age \& sex distribution

\begin{tabular}{lccc}
\hline Group & Male & Female & $\begin{array}{c}\text { Age (Yr) } \\
(\mathrm{m} \pm \mathrm{SD})\end{array}$ \\
\hline Case (Early onset MI) & 40 & 10 & $\begin{array}{c}36.62 \pm 4.46 \\
\text { before 45 yrs }\end{array}$ \\
Control (Late onset MI) & 37 & 13 & $\begin{array}{c}68.76 \pm 8.44 \\
(60-80)\end{array}$ \\
after 60 Yrs & & & $(60-45)$ \\
\hline
\end{tabular}

Parenthesis indicates range.
Table- II

Comparison of lipid profile, non-HDL-C and lipid ratios between cases \& control

\begin{tabular}{|c|c|c|c|}
\hline Parameters & $\begin{array}{c}\text { Case } \\
(\mathrm{n}=50)\end{array}$ & $\begin{array}{l}\text { Control } \\
(\mathrm{n}=50)\end{array}$ & $\begin{array}{c}\mathrm{p} \\
\text { value }\end{array}$ \\
\hline $\begin{array}{l}\mathrm{TC}(\mathrm{mg} \%) \\
(\mathrm{m} \pm \mathrm{SD})\end{array}$ & $178.36 \pm 43.16$ & $159.30 \pm 47.95$ & 0.04 \\
\hline $\begin{array}{l}\text { TAG(mg\%) } \\
(\mathrm{m} \pm \mathrm{SD})\end{array}$ & $180.64 \pm 88.24$ & $141.61 \pm 76.6$ & 0.02 \\
\hline $\begin{array}{l}\mathrm{LDL}-\mathrm{C}(\mathrm{mg} \%) \\
(\mathrm{m} \pm \mathrm{SD})\end{array}$ & $99.76 \pm 37.68$ & $95.68 \pm 39.02$ & 0.60 \\
\hline $\begin{array}{l}\mathrm{HDL}-\mathrm{C}(\mathrm{mg} \%) \\
(\mathrm{m} \pm \mathrm{SD})\end{array}$ & $37.96 \pm 11.55$ & $33.88 \pm 10.12$ & 0.06 \\
\hline $\begin{array}{l}\text { Non HDL-C } \\
\text { (mg \%) (median) }\end{array}$ & 134.50 & 132.00 & 0.15 \\
\hline $\begin{array}{l}\text { TC/HDL-C ratio } \\
\text { (median) }\end{array}$ & 4.59 & 4.70 & 0.97 \\
\hline $\begin{array}{l}\text { LDL-C/HDL-C } \\
\text { ratio (median) }\end{array}$ & 2.91 & 2.70 & 0.87 \\
\hline $\begin{array}{l}\text { TAG/TC ratio } \\
\text { (median) }\end{array}$ & 1.14 & 0.96 & 0.03 \\
\hline
\end{tabular}

\section{Discussion}

Present study showed the serum TC and TAG conc. significantly high in cases in comparison to control. This is well in line with the different studies done abroad. ${ }^{12-15}$ It is well known that $70 \%$ of circulating total cholesterol is carried by LDL particles. Increased TC in our cases inspite of similar LDL-C between cases \& control might be due to the predominance of other cholesterol containing lipoproteins e.g. Very Low Density Lipoprotein (VLDL), Intermediate Density Lipoprotein (IDL) \& chylomicron remnant which are highly atherogenic \& could be incriminated for early onset MI. Hypertriglyceridaemia brings qualitative changes on LDL particles to make them small dense LDL which are more atherogenic but contain less cholesterol in comparison to other large LDL subtype. Probably there is predominance of small dense LDL in early onset MI, because of which with respect of LDL-C early \& late onset MI patients found to be identical. Hypertriglyceridaemia also affects the HDL particles to be transformed into $\mathrm{HDL}_{1}$ subtype which is claimed to be atherogenic or not antiatherogenic. So it is possible that relatively atherogenic HDL subtypes $\left(\mathrm{HDL}_{\mathrm{T}}\right)$ are predominant in early onset MI because of which they manifest the disease in younger age in spite of normal HDL-cholesterol. Therefore 
Hypertriglyceridaemia probably gets linked to early onset MI through its influence in the qualitative change of LDL \& HDL-Cholesterol in the direction of higher atherogenic potential as revealed in our study.

This study showed no difference between cases and control with respect to HDL-C concentration inspite of high TAG concentration in cases. This finding clearly contradicts others ${ }^{16,17}$. HDL particles are of two distinct subclass; one is small, dense, relatively cholesterol enrich $\mathrm{HDL}_{1}$ containing both apo A-I \& apo A-II which is suspected to be atherogenic or not antiatherogenic; another is large, buoyant, cholesterol poor $\mathrm{HDL}_{2}$ containing only apo-A-I which is convincingly antiatherogenic ${ }^{18}$. Therefore the present picture of our study could probably be explained by the predominance of less atheroprotective or atherogenic $\mathrm{HDL}_{1}$ in cases \& antiatherogenic $\mathrm{HDL}_{2}$ in control. Since $\mathrm{HDL}_{2}$ is cholesterol poor relative to $\mathrm{HDL}_{1}$, so probably the number of $\mathrm{HDL}_{2}$ particle is more in control compared to that of $\mathrm{HDL}_{1}$ particle in cases since the HDL-C concentration is similar in both cases and control. The predominance of $\mathrm{HDL}_{1}$ in cases explain the propensity of $\mathrm{MI}$ in younger age which our study has revealed. The traditional view of hypertriglyceridaemia leading to reduced HDL-C in fact points to the loss of atheroprotection. In our early onset MI patients probably there is loss atheroprotection due to the predominance of atherogenic $\mathrm{HDL}_{1}$ although HDL-C concentration not that much reduced.

This study has revealed no significant difference between cases and control with respect to TC/HDL-C ratio \& LDL-C/HDL-C ratio. When compared between cases \& control both LDL-Cholesterol \& HDLCholesterol showed no difference; that is why probably the LDL-C/HDL-C ratio also showed no difference between cases \& control. Regarding the TC/HDL-C ratio it was expected to be higher in cases since the TC was higher in cases with HDL-C statistically identically between cases \& control. In fact from the view point of numerical figures HDL-C also found higher in cases than control although it failed to reach the statistical significance. This could be the probable explanation of no significant difference of TC/HDL-C ratio between cases \& control.

TAG/TC ratio in early onset MI of this study found significantly raised compared to late onset MI. In fact both TC \& TAG were significantly higher in cases compared to control but disproportionately there was more raise of TAG compared TC with the consequential increased ratio of TAG/TC in cases. The numerical ratios of TAG/TC in cases \& control of our study found $1.14 \& 0.96$ respectively. The ratio 1.14 indicates the Familial Combined Hyperlipidaemia (FCHL) rather than the isolated hypertriglyceridaemia. Austin \& his co-workers in their $20 \mathrm{yr}$. prospective study proposed that there is 1.7-10 fold increased risk of premature CAD in FCHL. So the finding of FCHL in our cases of early onset MI seems to be befitting in light of the above mentioned prospective study. This study has revealed no significant difference between cases \& control with respect to the non-HDL cholesterol. Since the majority of non-HDL-C is LDL-C \& the LDL-C found identical in both case \& control so is the picture of non-HDL cholesterol.

\section{Conclusion:}

Hypercholesterolemia and hypertriglyceridaemia are associated with early onset myocardial infarction.

\section{References:}

1. Piazza, A 2001, 'Genetics and early-onset myocardial infarction', Ital Heart Journal, vol. 2, pp. $31 \mathrm{~S}-33 \mathrm{~S}$.

2. Klein, LW \& Nathan, S 2003, 'Coronary artery disease in young adults', J Am Coll Cardiol, vol. 41, pp. 529-531.

3. Trehan, N, Kishore, S \& Rissam, HS 2001, 'Coronary Artery Disease in Young Indians', Journal, Indian Academy of Clinical Medicine, vol. 2, no. 3, pp. 128 132.

4. Mammi, MVI, Parithran, P \& Rahman, PA 1991, 'Acute MI in North Kerala. A 20 yr hospital based study', Indian Heart J, vol. 43, pp. 93-96.

5. Negus, BH, Williard, JE \& Glamann, DB 1994, 'Coronary anatomy and prognosis of young asymptomatic survivors of MI', Am J Med, vol. 96, pp. 354-358.

6. Zambon, A, Brown, BG, Deeb, SS \& Brunzell, JD 2006, 'Genetics of apolipoprotein B and apolipoprotein A1 and premature coronary artery disease', Journal of Internal Medicine, vol. 259, pp. 473-480.

7. Puchois, P, Kandoussi, A \& Fievet, P 1987, 'Apo A-I containing LP in CAD', Atherosclerosis, vol. 68, pp. 35-40.

8. Allain, CA, Poon, LS, Chan, CGS, Richmond, W \& Fu, PC 1974, 'Enzymatic determination of serum 
total cholesterol', Clinical Chemistry, vol. 20, pp. 470476.

9. Bucolo, G \& David, H 1973, 'Quantitative Determination of Serum Triglycerides by the Use of Enzymes', Clin. Chem, vol. 19, no. 5, pp. 476-482.

10. Lopes-Virella, MF, Stone, P, Eills, P \& Colwell, JA 1977, 'Cholesterol Determination in High-Density Lipoproteins Separated by Three Different Methods', Clin. Chem, vol. 23, no. 5, pp. 882-884.

11. Friedewald, WT, Levy, RI \& Fredrickson, DS 1972, 'Estimation of LDL-cholesterol in plasma without use of the preparative ultracentrifuge', Clinical Chemistry, vol. 18, no. 6, pp. 499-502.

12. Austin, MA, Mcknight, B \& Edward, KL 2000, 'Cardiovascular disease mortality in familial forms of hypertriglyceridaemia: a 20 year prospective study', Circulation, vol. 101, pp. 2777-2782.

13. Isser, HS, Puri, VK, Narain, VS, Saran, RK, Dwivedi, SK \& Singh, S 2001, 'Lipoprotein (a) and Lipid Levels in Young Patients with Myocardial Infarction and Their First - Degree Relatives', Indian Heart J, vol. 53, pp. 463-466.
14. Miremadi S, Sniderman A \& Frohlich, J 2002, 'Can Measurement of Serum Apolipoprotein B Replace the Lipid Profile Monitoring of Patients with Lipoprotein Disorders?', American Association for Clinical Chemistry, vol. 48, pp. $484-488$.

15. Molmberg, K, Barenholm, P \& Hamsten, A 1994, 'Clinical and biochemical factors associated with prognosis after myocardial infarction at a younger age', J Am Col Cardiol, vol. 24, pp. 592-594.

16. Singh, SP \& Sen, P 2003, 'Coronary heart disease: The changing Scenario' Indian j. Prev. Soc. Med, vol. 34, no (1 \& 2), pp. $74-80$.

17. Mohan, V, Deepa, R, Haranath, SP, Premalatha, G, Rema, M, Ganapathi, N \& Enas, EA 1998, 'Lipoprotein (a) is an Independent Risk Factor for Coronary Artery Disease in NIDDM Patients in South India', Diabetes Care, vol. 21, no. 11, pp. 1819 -1823 .

18. Maciejko, JJ, Holmes, DR \& Kottke, BA 1983, ‘Apo A-I as a marker of angiographically assessed CAD', N Engl. J. Med, vol. 309, pp. 385-389. 